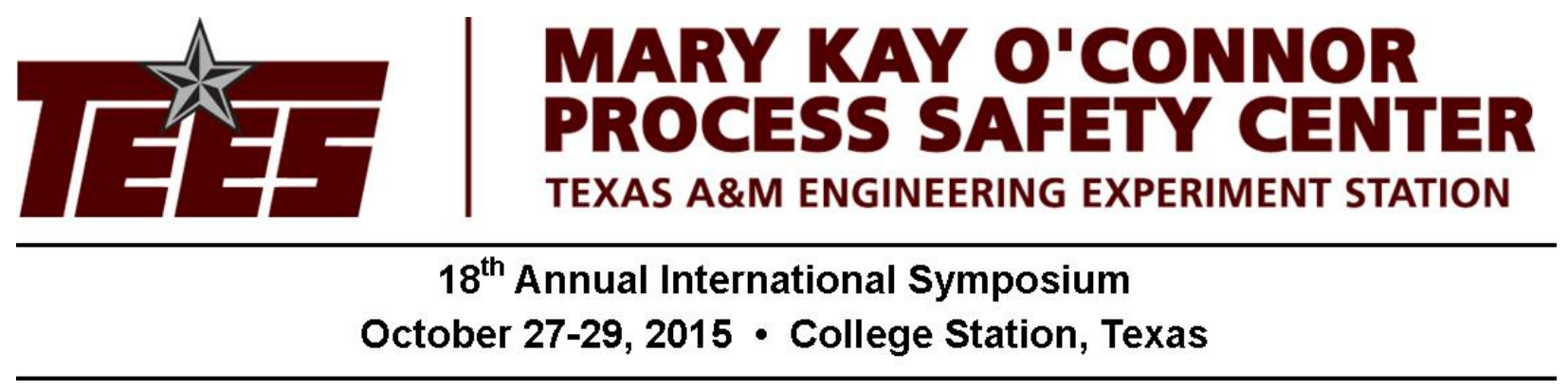

\title{
Quantification of the Thermal Hazard from Metallic and Organic Dust Flash Fires
}

\author{
Michael C. Stern ${ }^{\dagger}$, J. Rosen, A. Ibarreta, R. Ogle, and T. Myers \\ Exponent, Inc. \\ Natick, MA 01760
}

† Presenter E-mail: mstern@exponent.com

\begin{abstract}
An in-house constructed nominally 20-L flash fire apparatus was used to evaluate and compare the flash fires fueled by an organic dust (non-dairy coffee creamer) a metal dust (aluminum) and a flammable gas (methane). Dispersion was achieved using an injection system similar to the injection systems found in standard Siwek 20-L combustion chambers and a 10-J spark igniter was used to ignite the fuels. A heat flux gauge, thermocouples, an Infrared video camera, and an HD video camera were all used to evaluate the severity of the flash fires. Multiple concentrations of dusts and a stoichiometric methane mixture were tested. All measurement methods showed reasonable agreement when ranking the severity of different deflagrations, but thermocouple and heat flux gauge measurements were sensitive to the position of the flame, leading to some inconsistency. IR video measurements provided fireball dimensions and growth rates, and relative temperatures for dust-fueled deflagration, but were unable to accurately assess the high-turbulence premixed methane flash fires due to the high burning velocities and 30 frames per second limitation. The IR camera was also limited to $1200^{\circ} \mathrm{C}$, which is inadequate for the temperature of some metal dust deflagrations, including aluminum and requires adjustment of the material emissivity, which would require additional analysis and testing. Measurement strategies for a next-generation flash fire testing apparatus are proposed based on the results of this study.
\end{abstract}

\section{Introduction}

Flash fires from flammable gases, vapors, and dusts represent a significant hazard at many industrial and commercial facilities. In 2008, 174 fatal occupational accidents occurred due to fires and explosions [1]. The thermal hazard due to flash fires from vapors and gases has been well-studied and models based on calculating the intensity of irradiation on nearby objects or personnel provide an effective framework to determine safe distances for separating hazard areas, selecting clothing, and protecting workers [2]. Flash fires fueled by combustible dusts pose a more complicated problem that is both more difficult to model and unique to individual 
sources of dust [3]. Whereas the properties of methane at one facility are likely very similar to those of methane at an entirely different facility halfway across the world, the property of aluminum dust at an electronics manufacturing plant may differ widely from aluminum dust at a recycling plant in the same town. The properties of an aluminum dust may vary widely within a single facility or at a single location over time. Furthermore, due to the radiative properties of burning dust clouds, dust flash fires will likely yield a higher level of radiant heat than energetically similar flammable gas flash fires.

The complexity of combustible dust fires and explosions originates from the lack of consistent and readily measureable fundamental properties. For gases and vapors, burning velocities, quenching distances, flame temperatures, combustion enthalpies, and heat capacities are all widely reported. For a given dust, even if the major chemical component (e.g., aluminum) is known, a multitude of other factors are necessary to estimate its flammability. These factors include, but are not limited to, particle size distribution, morphology and porosity, oxidation state, and moisture content [3-5]. Model efforts often rely on empirically measured values, such as burning velocities, which are only valid for the dust tested [6].

When assessing the explosion hazard of combustible dusts, enforcement agencies and NFPA standards frequently rely on experimental data of several explosion and ignition properties at each area or site where potentially combustible dust is present [7-10]. Tested properties include the maximum pressure rise $\left(\mathrm{P}_{\max }\right)$, deflagration index $\left(\mathrm{K}_{\mathrm{st}}\right)$, minimum explosible concentration (MEC), minimum ignition energy (MIE), and minimum autoignition temperature (MIT) among others.

There have been attempts to develop experimental apparatuses for the characterization of constant pressure dust flame propagation, but these have typically focused on the measurement of the burning velocity or dust flame temperature; they have not characterized the radiant heat flux from the fireball. Gao et al. used a combustion chamber with a square cross-section and a total volume of 3.2 liters to obtain flame visualization, flame temperature, and burning velocity measurements [4]. Skjold et al. used latex balloons with an initial volume of 34 liters in an attempt to achieve spherical flame propagation at constant pressure [11]. They were successful in obtaining flame visualization data, but the setup had insufficient resolution to permit calculation of burning velocities. Julien et al. also conducted experiments with spherical balloons with initial volumes of approximately 14 liters. They obtained burning velocity and flame speed measurements [12]. Cashdollar et al. conducted coal dust explosion temperature measurements in mine scale-experiments and in a constant volume 8-liter vessel [13], and later metal and elemental dust explosion measurements in a constant volume 20 -liter vessel. While these studies are of fundamental interest, they do not shed light on the magnitude of hazard posed by flash fires of combustible dust.

The measurement of these properties, which are empirically related to explosion severity and ignitability, does provide an effective means of characterizing explosion hazards. However, we have shown in a previous paper that the $\mathrm{P}_{\max }$ and $\mathrm{K}_{\mathrm{St}}$ do not always correlate effectively to the severity of a flash fire hazard [14]. Three different dusts with similar $\mathrm{P}_{\max }$ and $\mathrm{K}_{\mathrm{St}}$, values as tested in a 20-L combustion chamber, were tested in an unconfined deflagration apparatus and showed significantly different flash fire behaviors.

Development of a flash fire testing strategy that can assess the hazard of flash fire from a given dust would fill an existing gap in the ability to assess flash fire hazards from combustible dust. Currently, the $\mathrm{P}_{\max }$ and $\mathrm{K}_{\mathrm{st}}$ are the primary indicators used for assessing flash fires, but are obtained through testing in a confined environment, most frequently in a 20 - $\mathrm{L}$ combustion 
sphere. The confined 20-L sphere does provide information on flame propagation and overpressure experienced during an explosion scenario, but does not represent the conditions of a flash fire.

In this paper, we further refine our testing approach to include temperature and heat flux measurements of the deflagration. Infrared (thermal) imagining video was also taken to provide information regarding the fireball temperature and size. Through evaluation of the different measurements techniques, strategies for a next-generation system with reliable quantification are proposed.

\section{Experimental Methods}

$\underline{\text { Materials }}$

Aluminum powder was purchased from Sigma-Aldrich. Non-Dairy coffee creamer was purchased from a local grocery store. Methane was obtained from a cylinder purchased from Air Gas. All samples were tested as received. Available data on the three fuel sources can be seen in Table 1.

Table 1. Properties of tested fuel sources

\begin{tabular}{|c|c|c|c|c|}
\hline Fuel Source & $\begin{array}{c}\text { Heat of } \\
\text { Combustion } \\
(\mathrm{kJ} / \mathrm{g})\end{array}$ & $\begin{array}{c}\text { Particle Size } \\
(\%<200 \text { mesh })^{1}\end{array}$ & $\begin{array}{c}\mathrm{P}_{\max } \\
(\mathrm{bar})\end{array}$ & $\begin{array}{c}\mathrm{K}_{\mathrm{St}} \text { or } \mathrm{K}_{\mathrm{G}} \\
(\mathrm{bar} \cdot \mathrm{m} / \mathrm{s})\end{array}$ \\
\hline $\begin{array}{c}\text { Aluminum } \\
\text { Powder }\end{array}$ & -61.8 & 100 & 8.0 & 209 \\
\hline $\begin{array}{c}\text { Non-Dairy } \\
\text { Coffee Creamer }\end{array}$ & -20.5 & 22 & 7.2 & 70 \\
\hline Methane $^{3}$ & -55.5 & N/A & 7.5 & 75 \\
\hline
\end{tabular}

1 Approximately $75 \mu \mathrm{m}$

${ }^{2}$ Values obtained from a single series performed based on the methodology described in ASTM E1226-12a

${ }^{3}$ Tested without air injection in a 20-L chamber using a spark igniter

\section{$\underline{\text { Experimental Apparatus }}$}

The unconfined nominally 20-L deflagration testing apparatus first described in Stern, et. al. was developed to replicate many of the conditions of the confined 20-L apparatus used in ASTM standards. Specifically, the injection and ignition mechanisms were reproduced and the level of turbulence is expected to be similar as a result of using the same injection nozzle within a similarly proportioned cylindrical geometry.

After ignition, the unconfined apparatus allows for the dust to expand outwards from the initial 20-L ignition zone. The subsequent unconfined deflagration is indicative of a selfsustaining combustion. It should be noted, however, that as with 20-L chambers, the use of powerful igniters does cause a hot region that may overdrive some propagation of the flames outside the initial 20-L area. For this paper, a 10 joule spark igniter was used to minimize the overdriving effects observed when using chemical igniters. While chemical igniters are typically timed to ignite 60 milliseconds after injection in 20-L testing, the spark igniter is triggered simultaneously with the injection and persists for about a second. 
Figure 1 shows a schematic diagram and photograph of the 20-L unconfined apparatus. During a test, the dust is loaded into the dust container, which is then pressurized to 20 barg with compressed dry air. After pressurization, the bottom solenoid valve is actuated releasing the dust and air into the 20-L ignition chamber.

In some tests the ignition chamber was partially evacuated to 0.8 bara prior to the injection and a plastic lid was used to seal the top of the chamber. In other tests, the chamber was not evacuated and no lid was placed on top of the chamber. Partial evacuation and use of the lid allowed for more control of the dust concentration during ignition, but increased test variability due to the unpredictable obstruction of the deflagration caused by the lid. Use of the lid also allowed for testing with gases.
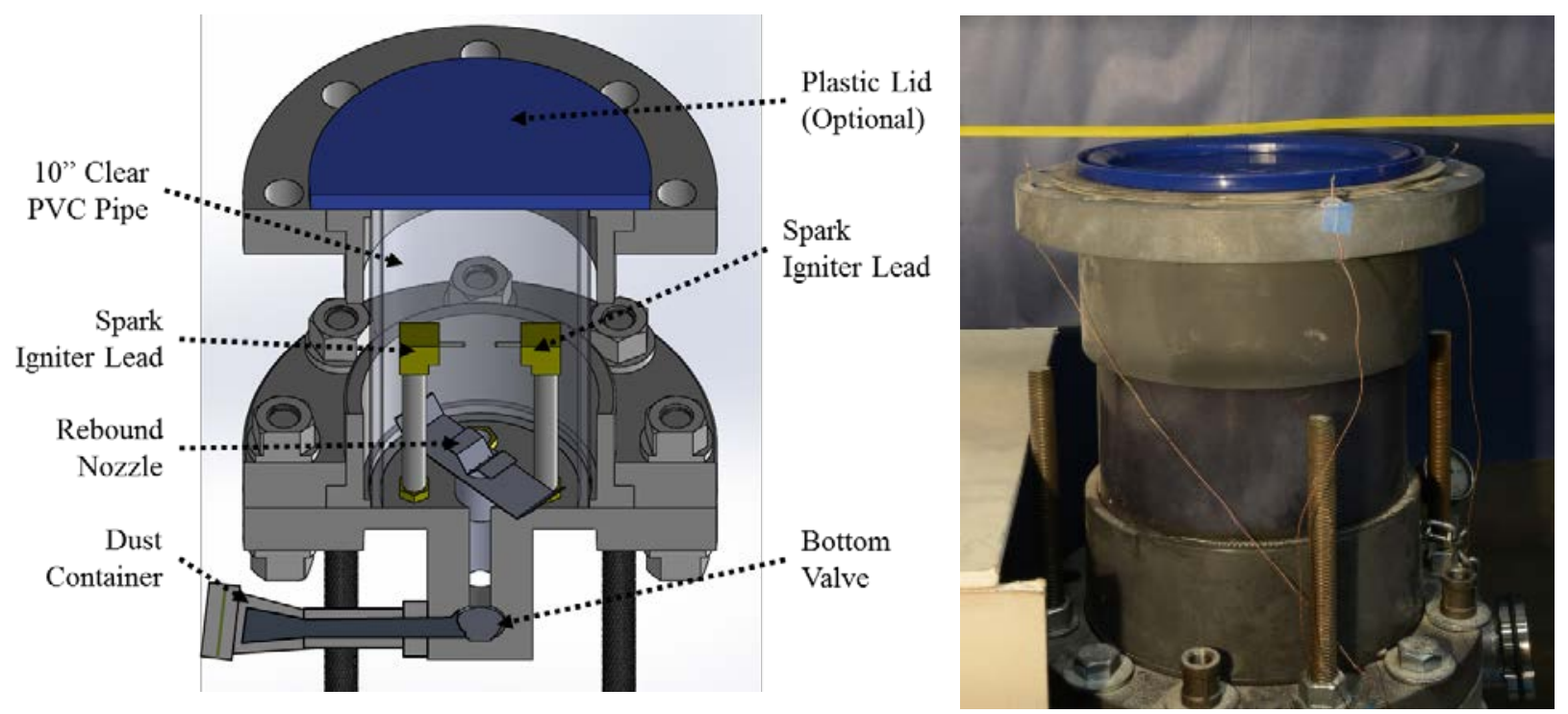

Figure 1. Schematic diagram (left) and photograph (right) of the 20-L flash fire apparatus. In the diagram, some elements are enlarged for visual clarity.

Simultaneously with the dust injection, a 10-J spark igniter at the center of the chamber was activated. If present, the plastic lid is ejected upwards first by the injected air and subsequent deflagration. Figure 2 shows representative images of the test system during operation.

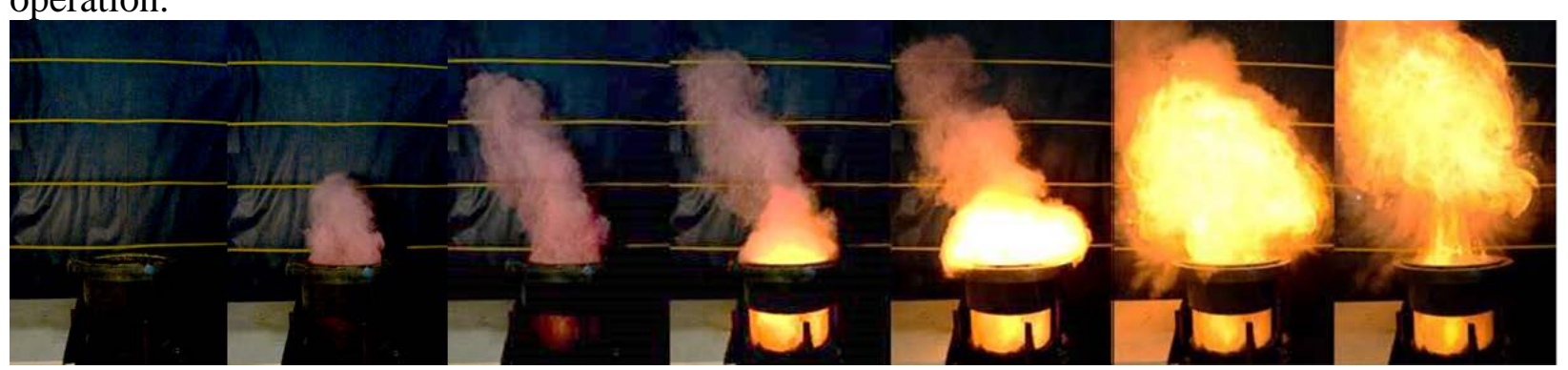

Figure 2. Representative still shots from a video taken of a deflagration of an organic dust. The dust is first injected, a spark at the center of the chamber ignites the dust, and then the flame propagates out of the chamber and through the dust cloud. Yellow lines behind the system are spaced at one foot intervals. 
Video recordings of the extent of the resulting fireball were used in our previous paper to characterize the intensity of the deflagration. For this paper, four thermocouples (36 gauge Type $\mathrm{K}$ from Omega Engineering) and a heat flux sensor (Schmidt-Boelter type from Medtherm) were placed 0.2 and 0.6 meters, respectively, from the center of the apparatus to quantify the temperature and heat release rates generated by the released deflagrations. The 0.6 meter distance of the heat flux sensor was chosen to yield data within the effective range of the sensor. The heat flux sensor read higher values when placed closer to the apparatus. Data was recorded at $1000 \mathrm{~Hz}$ using a Graphtec GL900 datalogger. The four thermocouples and the heat flux gauge were placed at a height approximately 3 centimeters and 15 centimeters, respectively, above the opening of the flange. A FLIR T400 Infrared Video Camera was also employed to further quantify the temperature and size of the deflagrations in addition to an HD video camera. For the IR camera, tests were repeated to allow measurement in the $0^{\circ} \mathrm{C}$ to $350^{\circ} \mathrm{C}$ range and in the $80^{\circ} \mathrm{C}$ to $1200^{\circ} \mathrm{C}$ range. The emissivity was set at 0.95 for the IR camera and the camera automatically calculated temperature based upon radiation in the 7.5 to $13 \mu \mathrm{m}$ wavelength range. The camera was not validated for flame temperature measurements and the measured values should be seen as a relative measure of temperature rather than absolute. The measured temperatures were significantly lower than those reported by others $[13,15]$. Similarly, two levels of exposure were recorded with the HD video camera to effectively capture the deflagrations of organic chemicals and the significantly more luminous aluminum deflagrations. HD video was recorded with a Nikon D7100 DSLR with a shutter speed of $400 \mathrm{~Hz}$.

\section{Results and Discussion}

The results of the testing were examined to elucidate the reliability of four different measurement techniques: regular video, infrared video, thermocouples, and a heat flux gauge. The goal of the testing was to determine the advantages and disadvantages of the different measurement methods to develop the best strategies for quantification of flash fire hazards in a future system.

\section{$\underline{\text { Regular and Infrared Video }}$}

Representative still frames from regular videos of deflagrations of non-dairy coffee creamer, aluminum, and methane can be seen in Figures 3 to 5 .

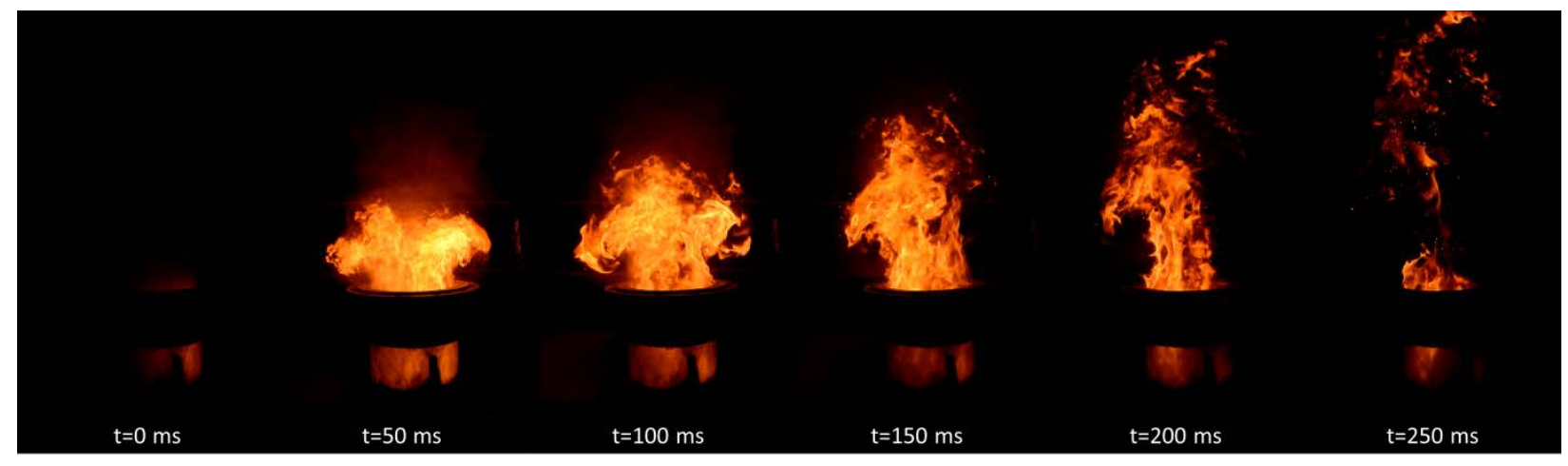

Figure 3. Still frames from video of a deflagration of 10 grams of non-dairy coffee creamer tested without a lid or evacuation of the chamber. 


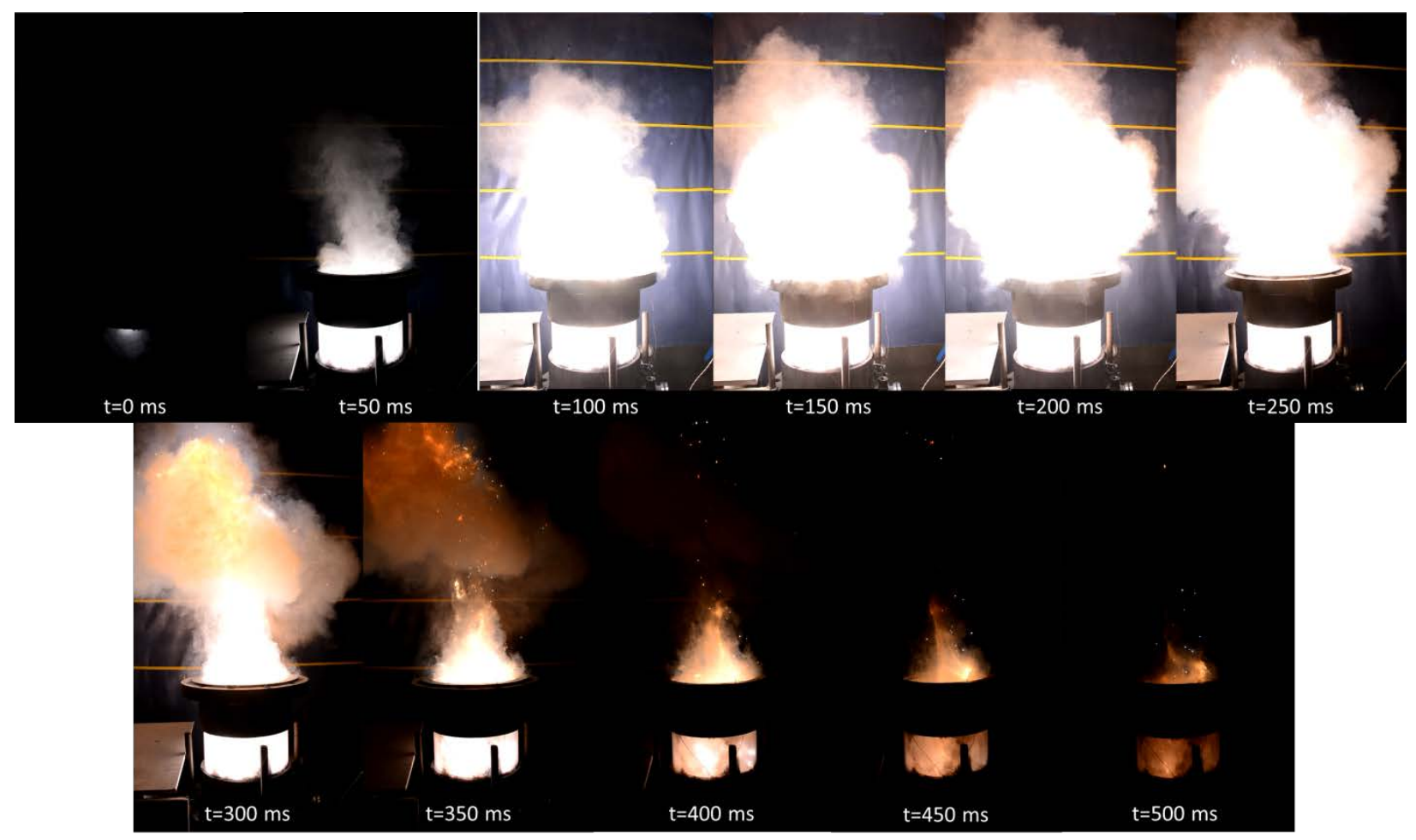

Figure 4. Still frames from video of a deflagration of 10 grams of aluminum powder tested without a lid or evacuation of the chamber.
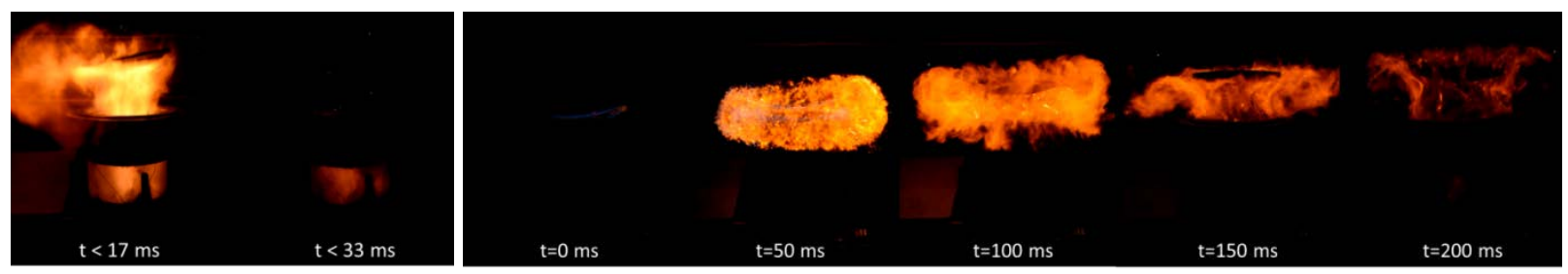

Figure 5. Still frames from video of a deflagration of 1.5 grams of methane with evacuation followed by air injection (left) and without air injection (right). Due to the relatively low emission of light from the deflagration without air injection, the video was recorded at a higher ISO (more exposure) than the other videos in Figures 3-5.

Video recordings provide significant insight into the size and intensity of a deflagration based on the extent of the visual fireball and luminance. As can be seen in Figures 3 and 4, the video effectively displays that the aluminum deflagration is larger, more intense, and more persistent than the coffee creamer deflagration as would be expected. While video was only recorded at 60 fps for this paper, high-speed video recording is a widely accessible tool that could be implemented as a measurement technique. Videos are effective at evaluating deflagrations that generate fireballs at inconsistent directions since they can be positioned to record a large area and are still effective even if pointed off-center of an irregular shaped flame.

Drawbacks of regular video include that the choice of exposure is not trivial and meaningfully impacts the results. Regular video provides information regarding the luminance of an event, which is correlated to the temperature and heat flux, but is not a direct a measurement like the output of an infrared camera. 


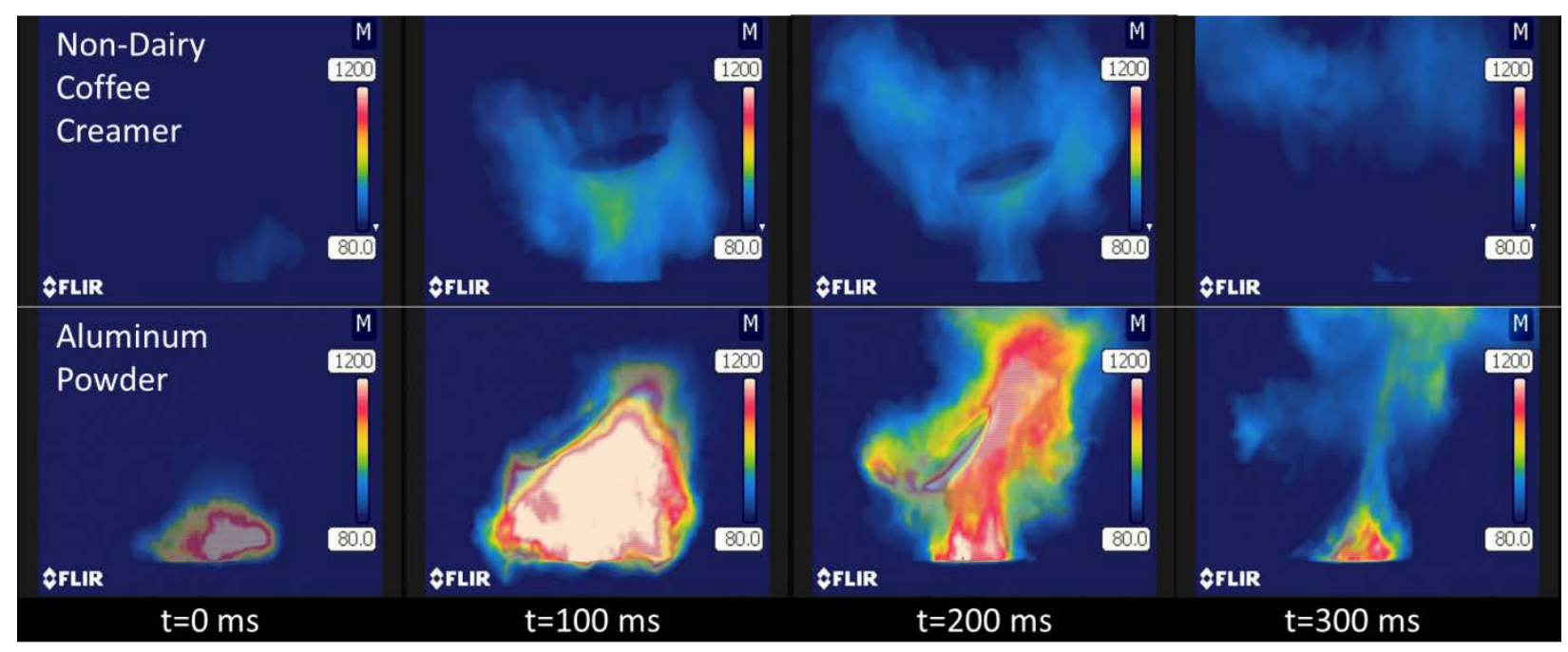

Figure 6. Still frames from IR video of deflagrations of 20 grams of non-dairy coffee creamer (top) and aluminum powder (bottom). Tests were performed with the chamber initially partly evacuated and sealed with a plastic lid.

Still frames from infrared videos of non-dairy coffee creamer and aluminum powder can be seen in Figure 6. Still frames from non-dairy coffee creamer deflagrations at multiple dust loadings can be seen in Figure 7. Infrared measurements possess many of the same advantages of regular video including a large recording area and wide availability while also providing heat flux data. Through analysis of infrared images, the size, and speed of the fireball can be ascertained, the irradiation of the fireball can be estimated and hot but non-luminous regions can still be identified. The temperatures reported by the IR camera should be seen as relative indicators of the thermal radiation and not absolute temperature measurements. Further development of an IR system could allow for quantitative measurements of heat flux and temperature.

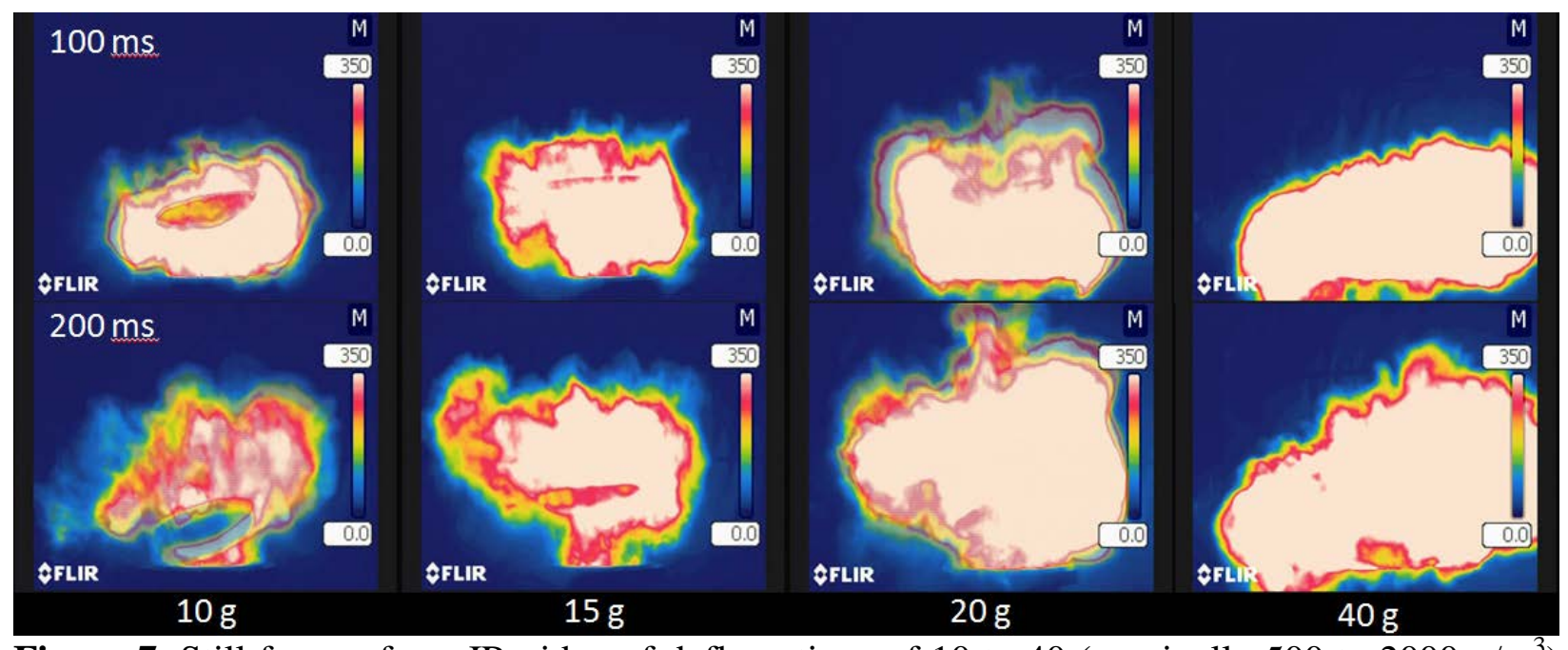

Figure 7. Still frames from IR video of deflagrations of 10 to 40 (nominally 500 to $2000 \mathrm{~g} / \mathrm{m}^{3}$ ) grams of non-dairy coffee creamer at 100 milliseconds after ignition (top row) and 200 
milliseconds after ignition (bottom row). Tests were performed with the chamber initially partly evacuated and sealed with a plastic lid.

Infrared imaging is limited, however, by the maximum measureable values. As can be seen in Figure 6, the aluminum deflagrations exceed the measureable limits of the device. Aluminum deflagrations can burn in excess of $2000^{\circ} \mathrm{C}$ [15], well exceeding the range of most IR cameras. With irradiation being a function proportional to the fourth power of temperature, this represents an intolerable amount of error for testing of metallic dusts.

Properly analyzed, the images could provide sufficient information to estimate the heat flux being emitted from the deflagration. Figure 8 shows an analysis of images from coffee creamer and aluminum IR videos with curves indicated the number of pixels above a given temperature over time.
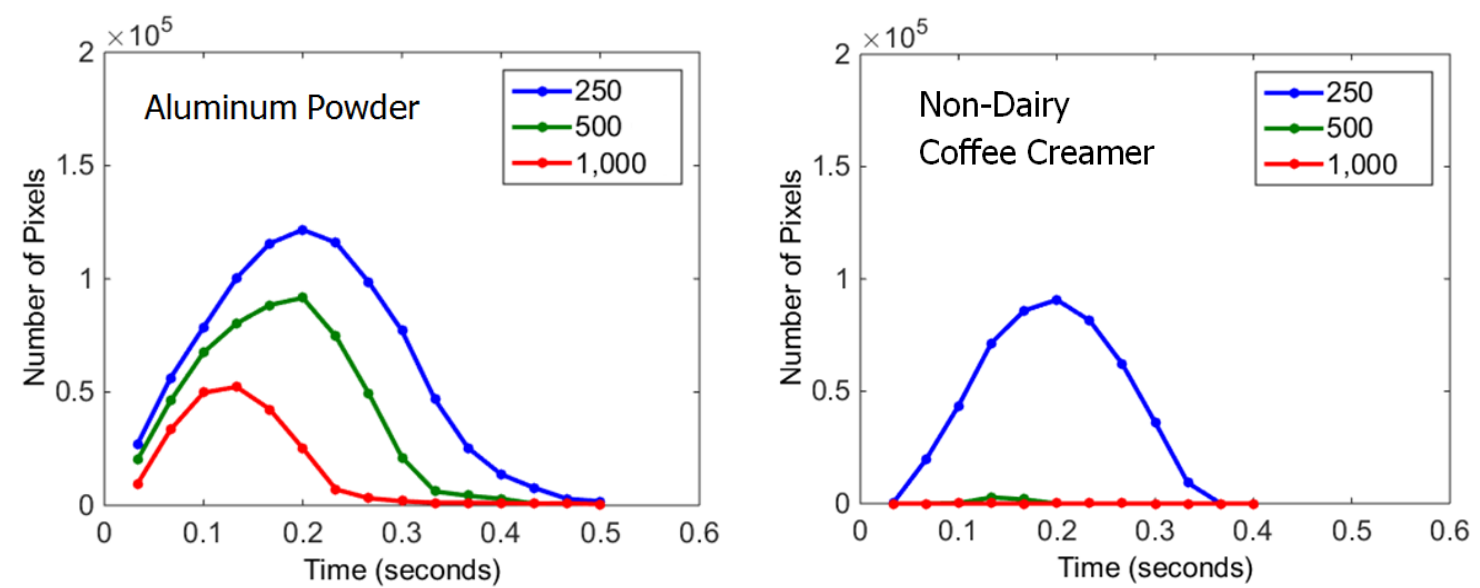

Figure 8. Analysis of IR videos of deflagrations of 20 grams of Aluminum (left) and non-dairy coffee creamer (right).

\section{Thermocouples and Heat Flux Gauges}

Thermocouples and heat flux gauges provide an alternative method for assessing the severity of the produced flash fires. Examples of data taken by the heat flux gauges and thermocouples for non-dairy coffee creamer and aluminum powders are shown in Figures 9 and 10. As expected, the measured temperatures and heat flux are significantly higher for the metal aluminum powder than for the organic coffee creamer. 

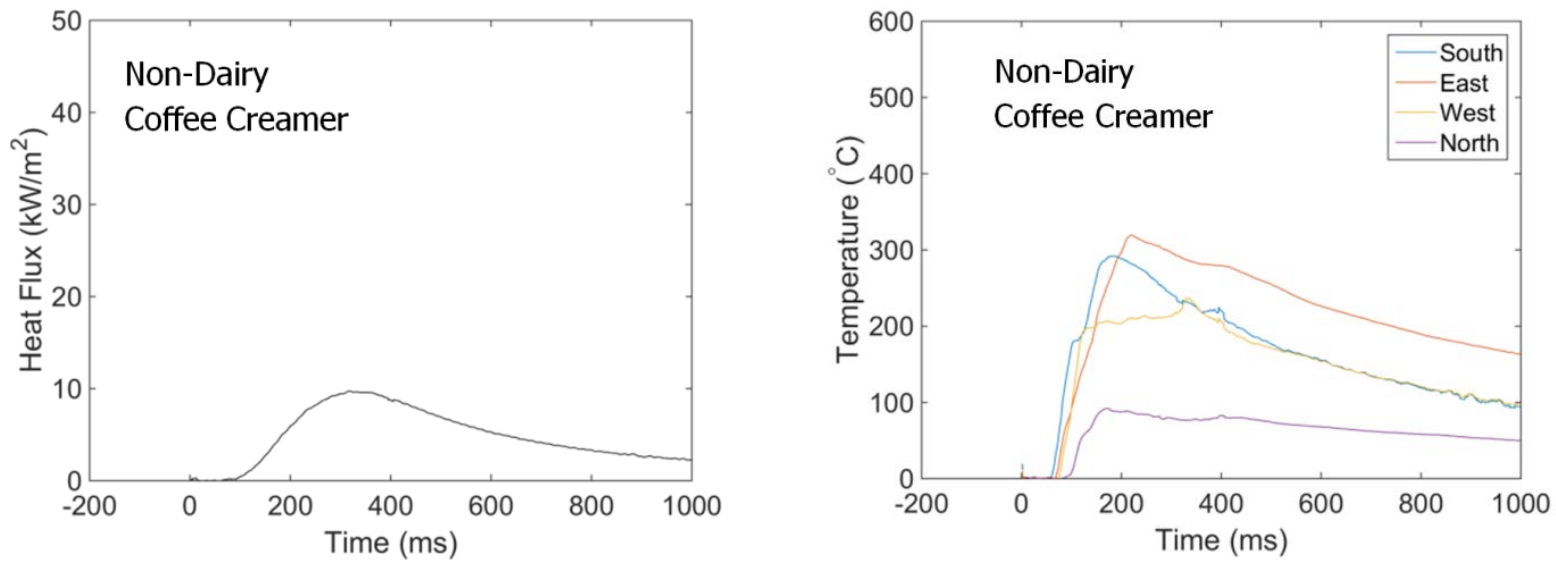

Figure 9. Representative plots of heat flux (left) and thermocouple (right) data for a deflagration of 20 grams of non-dairy coffee creamer.
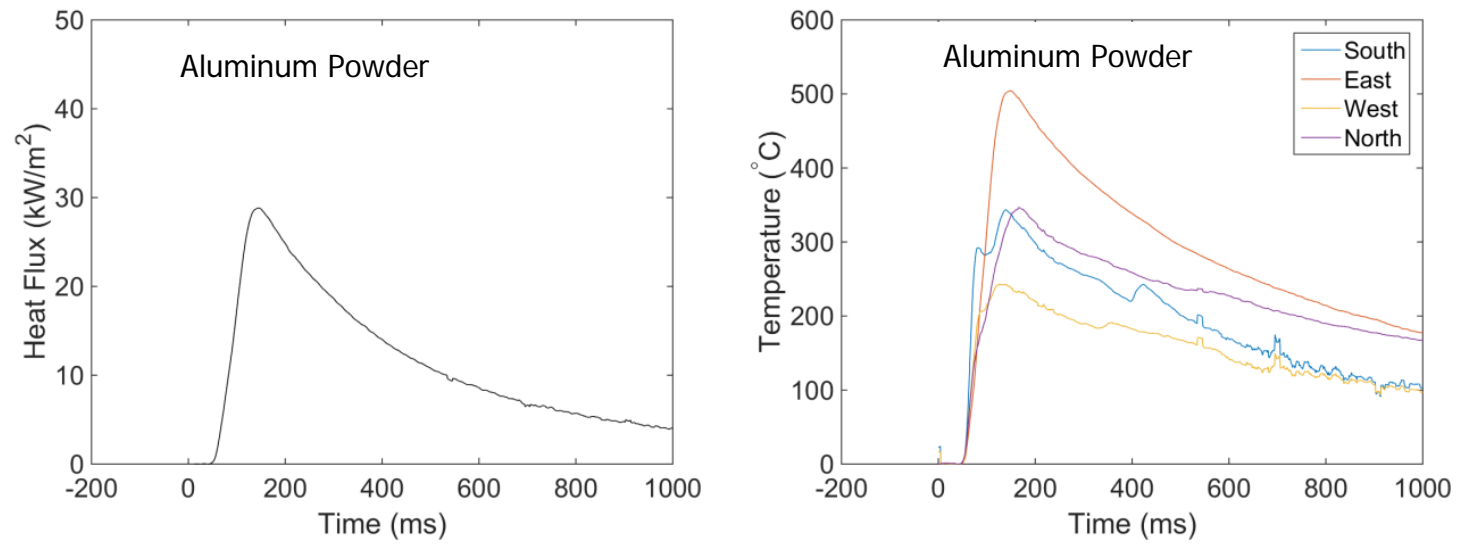

Figure 10. Representative plots of heat flux (left) and thermocouple (right) data for a deflagration of 20 grams of aluminum powder . 


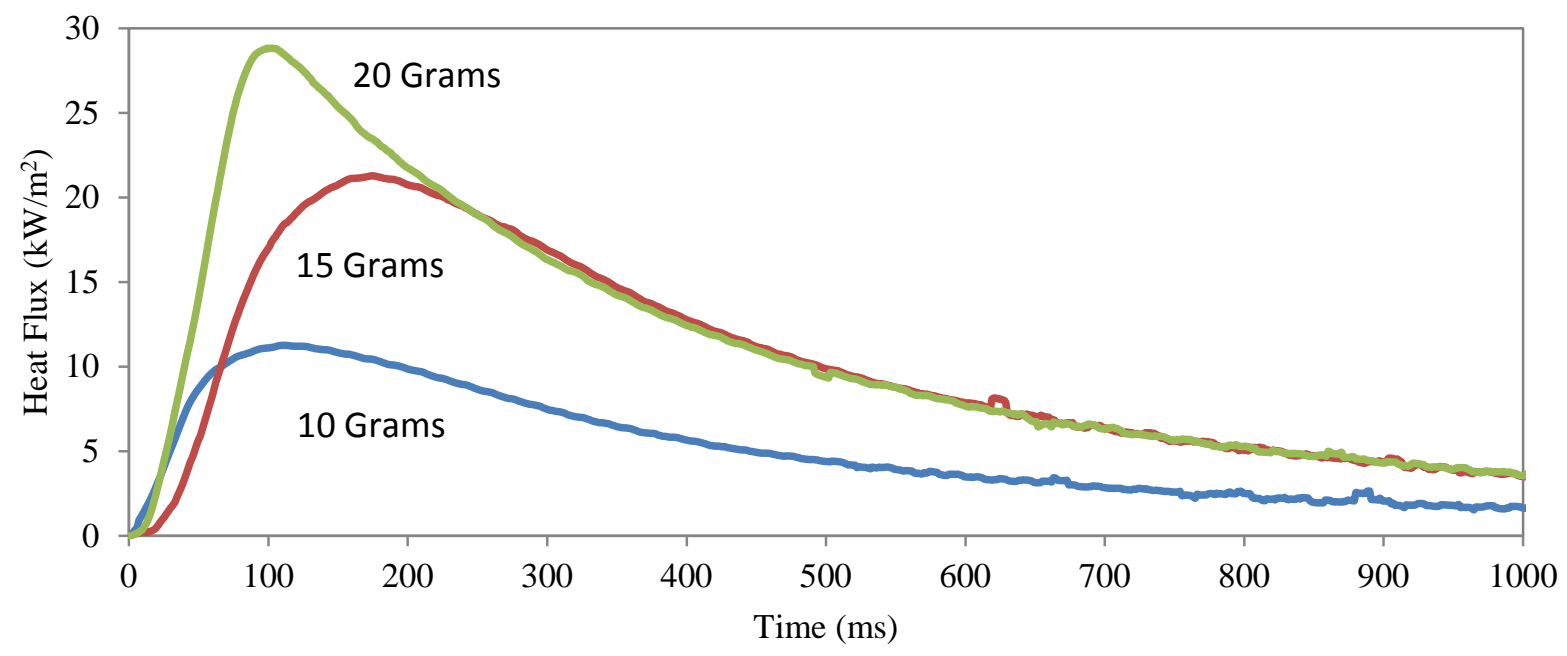

Figure 11. Heat flux measurements for 10, 15, and 20 gram deflagrations of aluminum powder.

When position far enough away from the center of the deflagration, thermocouples and heat flux gauges will not be overwhelmed by the intensity of aluminum fueled flames. Therefore, unlike the IR camera, heat release rates can be compared for all fuel types. Figure 12 shows heat flux gauge and thermocouple data plotted as a function of aluminum and non-dairy coffee creamer loading.

The average of the peak temperatures for each of the four thermocouples is taken to produce a representative value. A representative value for the heat flux gauge is the integral of the heat flux, which is equivalent to the total heat transferred. Equivalently, the highest peak temperature of the four thermocouples or the maximum observed heat flux could also have been used with little disturbance to the trends. Figure 13 shows the significant and linear correlations between the different metrics for the thermocouple and heat flux data sets.
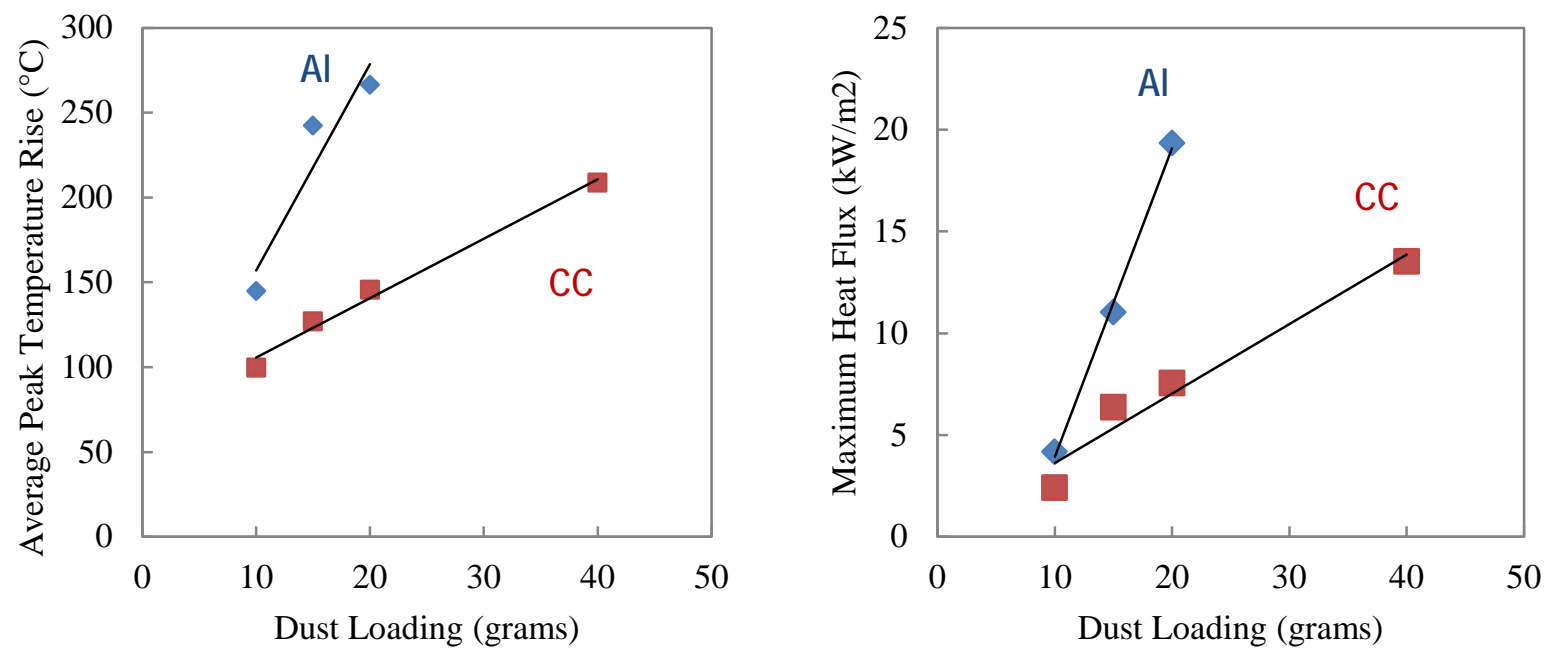

Figure 12. Average peak temperature (left) and total heat transferred (right) as a function of dust loading for aluminum (blue diamonds) and non-dairy coffee creamer (red squares). All points based are averages of two or three trials. 

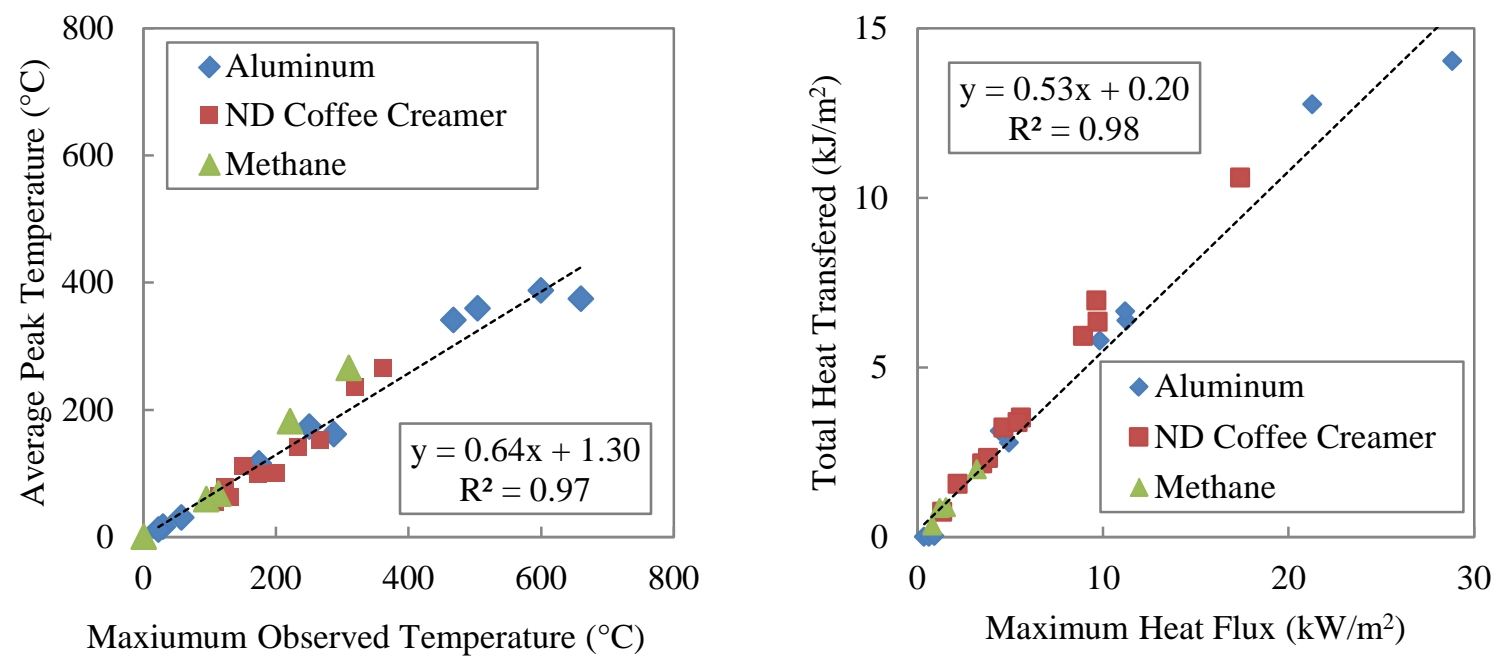

Figure 13. Correlation plots of Average Peak Temperature Rise with Maximum Peak Temperature Rise (left) and Total Heat Transferred with Maximum Heat Flux (right).

The correlation between the heat flux gauge and the thermocouple data, however, shows significant scatter as shown in Figure 14. Furthermore, while the linear regressions of the data for aluminum and non-dairy coffee creamer yield lines with similar slopes and intercepts, the regression for methane is substantially different. The scatter is likely the result of the inconsistent direction of the deflagration and lid during testing. Evidence of this can be seen in in the temperature plots of Figures 9 and 10 where thermocouples placed at equal distances from the center of the apparatus yield substantially different temperatures indicating significant axial asymmetry in the deflagration.

The linear nature of the correlation between heat flux and temperature data is not intuitive since irradiation scales with the fourth power of temperature per the Stefan-Boltzmann law. However, due to the short time-scales of these deflagrations, the thermocouples are experiencing transient heating. Therefore, it is anticipated that the temperature of the thermocouple is proportional to the total quantity of heat transferred. This indicates that the thermocouple, when in this transient regime, is functioning as a calorimeter and measures the heat transferred to the thermocouple junction. 

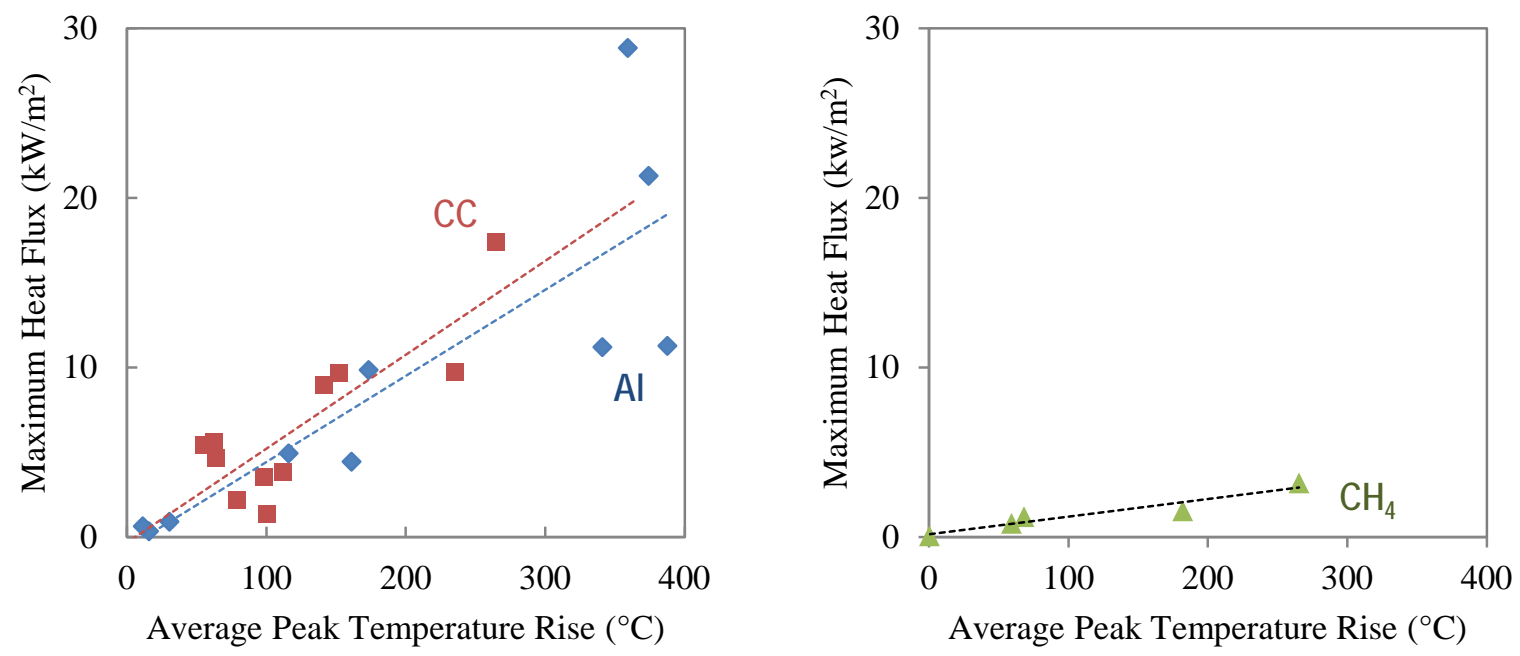

Figure 14. Correlation plots of Total Heat Transferred with Average Peak Temperature Rise for aluminum (blue diamonds) and non-dairy coffee creamer (red squares) (left) and methane (right).

The weakness of the heat flux and thermocouple measurements, is therefore, their dependence on a consistent deflagration shape or the sensors veiw factor. This can be forced through using a more confined geometry, such as a long cylinder, instead of allowing the deflagration to exit the cylinder and spread three-dimensionally. Resitriction in one dimension, however, changes the deflagration front from one with a constantly expanding surface area, to a front with a constant surface area. This may be problematic if a fully unconfined test is desired

Thermocouples, in addition to being highly sensitive to their placement with respect to the deflagration, also suffer from the inability to reach the peak temperatures expected at the center of an aluminum deflagration. Common type $\mathrm{K}$ thermocouples reach only $1250^{\circ} \mathrm{C}$ and more speciallized varieties based on platinum/rhodium mixes can reach up to $2000^{\circ} \mathrm{C}$, which still falls short of the aluminum flame temperature. The $50 \mathrm{~kW} / \mathrm{m}^{2}$ heat flux gauge, however, placed 0.6 meters from the apparatus, only reached $70 \%$ of its design limit in our testing. Heat flux sensors with slower response times, which are more widely available, can be used without significant loss in information if the correlation shown in Figure 13 is applied to translate total heat transferred to maximum heat flux. The results of all the testing are tabulated in Table 2.

Table 2. Tabulated average results for each set of conditions tested

\begin{tabular}{|c|c|c|c|c|c|c|}
\hline Chemical & $\begin{array}{c}\text { Loading } \\
\text { (grams) }\end{array}$ & Trials & $\begin{array}{c}\text { Peak } \\
\text { Heat } \\
\text { Flux } \\
\left(\mathrm{kW} / \mathrm{m}^{2}\right)\end{array}$ & $\begin{array}{c}\text { Average } \\
\text { Peak } \\
\text { Temperature } \\
\text { Rise }\left({ }^{\circ} \mathrm{C}\right)\end{array}$ & $\begin{array}{c}\text { Max } \\
\text { Percent of } \\
\text { IR Pixels } \\
\text { over 250 }\end{array}$ & $\begin{array}{c}\text { Max Percent } \\
\text { of IR Pixels } \\
\text { over 1000 }\end{array}$ \\
\hline $\begin{array}{c}\text { Aluminum } \\
\text { (no vacuum or } \\
\text { lid) }\end{array}$ & 10 & 2 & 4.7 & 139 & 52 & 17 \\
\hline Aluminum & 10 & 3 & 4.2 & 145 & 56 & 20 \\
\cline { 2 - 7 } & 15 & 3 & 11.0 & 242 & 69 & 49 \\
\hline
\end{tabular}




\begin{tabular}{|c|c|c|c|c|c|c|}
\hline & 20 & 2 & 19.3 & 266 & 66 & 25 \\
\hline $\begin{array}{c}\text { Coffee Creamer } \\
\text { (no vacuum or } \\
\text { lid) }\end{array}$ & 10 & 1 & 4.6 & 64 & 24 & 0.4 \\
\hline \multirow{3}{*}{ Coffee Creamer } & 10 & 2 & 2.4 & 100 & 16 & 0.3 \\
\cline { 2 - 7 } & 15 & 2 & 6.4 & 127 & 47 & 0.5 \\
\cline { 2 - 7 } & 40 & 2 & 13.5 & 209 & 51 & 0.9 \\
\hline $\begin{array}{c}\text { Methane } \\
\text { (quiescent) }\end{array}$ & $\begin{array}{c}1.5 \\
(10 \% \mathrm{v} / \mathrm{v})\end{array}$ & 2 & 2.4 & 224 & 14 & 0.7 \\
\hline $\begin{array}{c}\text { Methane } \\
\text { turbulent) }\end{array}$ & $\begin{array}{c}1.5 \\
(10 \% \mathrm{v} / \mathrm{v})\end{array}$ & 2 & 1.0 & 64 & 16 & 0.3 \\
\hline
\end{tabular}

\section{Conclusions}

Based on the assessment of the four measurement techniques used to quantify the flash fires generated by the unconfined deflagration apparatus, the heat flux gauge and IR camera were identified as providing the most information. The current IR camera, however, is not suitable for evaluation of metal deflagrations that exceed its temperature range. The heat flux gauge is sensitive to the direction of propagation of the deflagration, and must be positioned in a system in such a manner that a relatively constant view of the flame is achieved. Multiple heat flux gauges may be necessary to achieve this.

The data obtained in this study is only useful for comparative assessments of flash fire hazards, but is not yet transferrable for design purposes. When implemented in a next-generation flash fire testing apparatus, the quantitative techniques evaluated in this paper could be useful for more absolute assessments of flash fire hazards. Heat fluxes derived from the small scale tests can be scaled with appropriate models to identify safe distances at industrial facilities where flash fire hazards are present.

Standard flash fire hazard assessments could be used for the development of appropriate PPE standards when working in flash fire hazard areas. Currently, methods for evaluating the appropriate fire protective clothing for a methane flash fire are well known, but methods for evaluating appropriate clothing for dust flash fires are not well defined. Additionally, methods for determining of safe standoff distances from different dust flash fires are poorly understood.

Currently, NFPA standards including 652, 654, and 484 require engineering analyses to be performed to justify distances for separating flash fire areas, but do not provide specific guidance on how those analyses are to be performed. Models based on heat flux data obtained from a next-generation flash fire apparatus, could fill this role effectively. Identification of competent ignition sources may also be helped through the use a quantitative flash fire testing apparatus. 


\section{References}

1. Bureau of Labor Statistics. Oil and Gas Industry Fatal and Nonfatal Occupational Injuries. Available at http://www.bls.gov/iif/oshwc/osh/os/osar0013.htm.

2. The SFPE Handbook of Fire Protection engineering, Fourth Edition, National Fire Protection Association, 2008.

3. Myers, T. and Ibarreta, A. Tutorial on combustible dust, Process Safety Progress, 32, 298-306 (2013).

4. Gao, W., Dobashi, R.. Mogi, T. Sun, J., and Shen, X. Effects of particle characteristics on flame propagation behavior during organic dust explosions in a half-closed chamber, Journal of Loss Prevention in the Process Industries, 25: 993-999, 2012.

5. Proust, C. and Veyssiere, B. Fundamental properties of flames propagating in starch dustair mixtures, Combustion Science and Technology, 62: 149-172, 1988.

6. Skjold, T., Arntzen, B. , Hansen, O. , Taraldset, O. , Storvik, I. , \& Eckhoff, R. Simulating dust explosions with the first version of DESC. Process Safety and Environmental Protection, 83(2), 151-160, 2005.

7. OSHA, “Combustible Dust National Emphasis Program” CPL 03-00-006 (2007).

8. $\quad$ NFPA 484, Standard on Combustible Metals, 2015.

9. NFPA 654, Standard for the Prevention of Fire and Dust Explosions from the Manufacturing, Processing, and Handling of Combustible Particulate Solids, 2013.

10. $\quad$ NFPA 652, Standard on Combustible Dusts (Proposed Standard).

11. Skjold, T., Olsen, K., and Castellanos, D. A constant pressure dust explosion experiment. Journal of Loss Prevention in the Process Industries, 26:562-570, 2013.

12. Julien, P., Vickery, J., Whiteley, S., Wright, A., Goroshin, S., Bergthorson, J., and Frost, D. Effect of scale on freely propagating flames in aluminum dust clouds. Journal of Loss Prevention in the Process Industries, In Press, 2015.

13. Cashdollar, K, Hertzberg, M. Infrared Temperatures of Coal Dust Explosions, Combustion and Flame 51: 23-35, 1983.

14. Stern, M., Rosen, J., Ibarreta, A., Myers, T., and Ogle, R. Unconfined Deflagration Testing for the Assessment of Combustible Dust Flash Fire Hazards. Proceedings of the $11^{\text {th }}$ Global Congress on Process Safety, Austin, TX, 2015.

15. Cashdollar, K., Zlochower, I. Explosion temperatures and pressures of metals and other elemental dust clouds. Journal of Loss Prevention in the Process Industries, 20(4-6):3373482007. 